\title{
A PARTICIPAÇÃO DA SOCIEDADE NA ELABORAÇÃO E MONITORAMENTO DE POLÍTICAS PÚBLICAS EDUCACIONAIS: o caso do \\ Plano Municipal de Educação em Santana do Ipanema/AL
}

\author{
THE PARTICIPATION OF SOCIETY IN THE PREPARATION AND \\ MONITORING OF PUBLIC EDUCATIONAL POLICIES: the case of the \\ Municipal Plan of Education in Santana do Ipanema / AL
}

\begin{abstract}
Luciene Amaral da Silva ${ }^{1}$ Inalda Maria dos Santos ${ }^{2}$

Resumo

O artigo apresenta os resultados da pesquisa sobre a participação da sociedade na elaboração e monitoramento do Plano Municipal de Educação- PME, do município de Santana do Ipanema, estado de Alagoas. A pesquisa buscou analisar a presença/ausência da participação popular no processo de elaboração e monitoramento do PME. Para o desenvolvimento da pesquisa utilizouse a técnica de entrevista e observação direta das reuniões do Fórum Municipal de Educação. A temática é discutida à luz de Luck (2005), Saviani (2005), Dourado (2007), Bordignon (2009), Gadotti (2014), dentre outros autores que discutem sobre a importância do planejamento e participação popular.
\end{abstract}

Palavras-chave: Monitoramento. Planejamento. Participação Popular.

\section{Abstract}

The article presents the results of the research on the participation of society in the elaboration and monitoring of the Municipal Plan of Education - PME, in the municipality of Santana do Ipanema, state of Alagoas. The research sought to analyze the presence / absence of the people particpation in the SME development and monitoring process. For the development of the research was used the technique of interview and direct observation of the meetings of the Municipal Forum of Education. The theme is discussed in the light of Luck (2005), Saviani (2005), Dourado (2007), Bordignon (2009) and Gadotti (2014) among other authors who discuss the importance of popular planning and participation.

\footnotetext{
${ }^{1}$ Pedagoga, mestre em educação e doutoranda em educação -CEDU/UFAL. Professora da educação básica-rede estadual de Alagoas. E-mail. cieneamaral@hotmail.com

${ }^{2}$ Doutora em educação - Professora do Programa de Pós-graduação (PPGE) Centro de Educação CEDU/UFAL. E-mail: inaldasantos@hotmail.com
}

Revista de Administração Educacional, Recife, V. 1. No 2 -jul/dez. 2017 p. 37-48 
Keywords: Planning. Monitoring. Popular Participation.

\section{INTRODUÇÃO}

As políticas públicas surgem como materialização da redemocratização do país com intensidade na década de 1980. O planejamento educacional é uma necessidade de execução eficaz das políticas públicas e para ser efetivado, precisa da participação da população em seu acompanhamento e avaliação, no entanto, quando há participação da sociedade ela se restringe apenas ao processo de elaboração, deixando o monitoramento e a avaliação a cargo de profissionais, que em muitos casos, são representações dos governos do que dos interesses do povo.

O Plano Nacional de Educação, como planejamento educacional, discutido desde 1932 com os Pioneiros da Educação, está legitimado no art. 214 da Constituição Federal com o objetivo de articular e integrar as ações do poder público no tocante a educação. Contemplado de forma especifica na Lei de Diretrizes e Bases da Educação Nacional, Lei n. 9.394/1996, o Plano Nacional de Educação (PNE), mais uma vez, na sua segunda versão, aponta para a necessidade de (mais) participação popular e a articulação com os planos estaduais e municipais, com o intuito de promover o alinhamento entre os planos e garantir a execução das metas propostas ao longo de uma década.

A partir dessa discussão, municípios e estados foram convocados para reelaboar e muitos ainda elaborar seus planos de educação com a participação da sociedade, com o objetivo de garantir o alinhamento dos planos a ser executado na década de 2014 a 2024.

A partir da aprovação do PNE (2014-2024), os estados e municípios tiveram o prazo de um ano, para (re)elaborar seus planos de educação, no entanto foi constatado, a partir do site De Olho nos Planos, que acompanham a elaboração dos planos, grande parte dos municípios brasileiros ainda não tinham planos municipais de educação construídos.

Para orientar os municípios na (re) elaboração dos planos de educação, a União dos Dirigentes Municipais de Educação- UNDIME ficou responsável em ofertar

Revista de Administração Educacional, Recife, V. 1. № 2 - jul/dez. 2017 p. 37-48 
formação e acompanhar a construção e o monitoramento dos planos de educação dos municípios brasileiros através de suas secções regionais.

Para isso, foram convocados os técnicos das secretarias municipais de educação para estudo do caderno de orientação elaborado pelo MEC para subsidiar os municípios na fase de elaboração.

O estado de Alagoas foi dividido em polos para organizar as formações e garantir atendimento a todos os municípios. Concluída a fase de formação dos técnicos das secretarias municipais, o passo seguinte foi desenvolver em cada município a elaboração do Plano Municipal de Educação a partir dos passos apresentados pela sistemática de trabalho da UNDIME.

\section{CONTEXTUALIZAÇÃO DAS POLÍTICAS EDUCACIONAIS NO BRASIL}

As políticas públicas estão sendo tratadas por diversos autores (AZEVEDO,1997; GAHANEM, 2004; GOMES, 2011; SANTOS, 2011) como espaço de aprendizagem da democracia, através da participação da sociedade, e eles veem, nas políticas educacionais, a efetivação da aprendizagem democrática em âmbito escolar. Sendo assim, nas últimas três décadas, muito tem se discutido sobre políticas públicas no Brasil e no cenário acadêmico, os estudos têm se intensificado em torno dessa temática com base no momento histórico pelo qual o Brasil passa. Na produção intelectual, os estudos inscrevem-se de forma interdisciplinar nos diversos objetos de pesquisas que visam avaliar as ações do governo no âmbito social.

Desde o final dos anos de 1980 que os estudos e debates sobre políticas públicas no Brasil fortaleceram-se e trouxeram para o cenário nacional o debate sobre a responsabilidade do governo no campo social. As políticas públicas apresentam-se com o objetivo de atender às necessidades sociais de um povo que almejava a garantia dos diretos ora conquistados.

No contexto das políticas públicas, o termo política é utilizado como "uma construção político-social, produto da ação humana interessada" (GOMES, 2011, p. 22) e que se apresenta como o conjunto de ações provenientes do poder público para sanar as demandas sociais que estão prescritas na Constituição Federal, as políticas sociais

Revista de Administração Educacional, Recife, V. 1. № 2 - jul/dez. 2017 p. 37-48 
acabaram por ser uma forma de garantir os direitos que estão assegurados pela legislação. E a educação como política pública, apresenta-se nas agendas dos governos como um problema que pode resolver outros problemas.

Nessa direção, Azevedo (1997, p. 59) apresenta o conceito de política educacional "como programa de ações construídas também para atender objetivos e decisões políticas que se realiza por meio do Estado e se materializa nos espaços educacionais". Afirma também que na formulação das políticas educacionais não se pode ignorar as mudanças sociais pelas quais a educação vem passando nos últimos anos e como essas mudanças interferem na forma política de gestão da educação. Como a educação não pode ser desvinculada dos processos políticos, também não se deve formular uma política voltada para a educação em que será materializada na escola sem vislumbrar as necessidades da realidade educacional.

A escola deve ser considerada, quando forem pensadas políticas educacionais, como espaço de materialização e visualização das ações planejadas, como um ambiente de possibilidades e limitações na execução de tais políticas e que a estrutura deve ser pensada em primeiro plano para que a política realmente possa atingir seus objetivos, mesmo que esses objetivos não tenham sido construídos partindo da escola. É necessário perceber que existem mudanças no percurso que uma política educacional faz até chegar à escola. Os que pensam as políticas, muitas vezes, não têm a vivência das relações que se processam na escola, daí deve-se contar com a possibilidade de ressignificação da política pelo professor que irá ser o responsável último em transferila para o aluno. Assim, Azevedo (1997, p. 59) afirma que "não se pode esquecer que a escola e principalmente a sala de aula, são espaços em que se concretizam as definições sobre a política e o planejamento que as sociedades estabelecem para si próprias, como projeto ou modelo educativo que se tenta por em ação".

As políticas públicas voltadas para a educação materializam-se através da legislação, programas e projetos destinados a modernizar a educação com metas para democratização do ensino e da gestão da escola (AZEVEDO, 1997).

Segundo Saviani (2005, p. 29), "a política educacional diz respeito às medidas que o poder público toma relativamente aos rumos que se deve imprimir à educação". No entanto, grande parte das políticas públicas é planejada sem a participação da 
sociedade, cabendo às escolas o papel de executoras das ações, gerando resultados defasados de aprendizagem quando são medidos em avaliações padronizadas e homogeneizadas, responsabilizando a escola pelo seu fracasso. De acordo com Romanelli (1991, p. 43) "todas essas reformas, porém, não passaram de tentativas frustradas e, mesmo quando aplicadas representava o pensamento isolado e desordenado dos comandos políticos [...].”

Desde a Constituição Federal de 1988, a Lei de Diretrizes e Bases da Educação Nacional - LDB de 1996 até o Plano Nacional de Educação - PNE de 2001 que foram consolidadas legalmente as ações destinadas à implementação, isto é, pôr em prática as políticas educacionais no país. É interessante observar que para cada momento histórico, as políticas públicas tiveram um determinado objetivo para um fim. Isso significa que "qualquer política pública, não é um fenômeno monocausal. Basta considerarmos que, por exemplo, sobre a formulação de uma política pública de educação pesa, explicita ou implicitamente, a divisão da população em classes sociais" (GOMES, 2011, p. 21).

As políticas educacionais existem para atender determinados propósitos oriundos de um projeto de sociedade esquematizado para sua implantação. Desde a gestão da educação como forma ampla de administração da educação até a gestão da escola, as políticas educacionais encontram espaço para materializar-se e concretizar esse projeto de sociedade.

2.1 A participação como elemento materializador da democracia na construção de políticas públicas

De acordo com Motta (1987), os estudos sobre a participação na gestão da escola tiveram início nos anos de 1960 e 1970 nos Estados Unidos e Europa. O autor afirma que a participação surgiu como forma de controlar o conflito, trazer o povo à participação era mantê-los passivos, que a força física não estava mais sendo eficaz.

Os regimes ditatoriais, que faziam o povo à força obedecer as suas regras, deram lugar a um modelo de gestão em que a sociedade pudesse participar da escolha desses governos através do voto. A democracia tornou-se uma construção individualizada 
(BOBBIO, 1986) de um grupo elitizado que foi direcionada a uma sociedade com o objetivo de gerar convivência pacífica em períodos pós-ditatoriais.

A participação é o pilar na forma de administração com base em princípios democráticos, presentes nas discussões desde 1968. Gutierrez e Catani (1998, p. 60) afirmam que a introdução dos estudos sobre a participação nas instituições sociais significou nada menos que uma revisão dos pressupostos teóricos do taylorismo e a sua substituição, mesmo que muito lentamente, por valores contemporâneos, como flexibilidade, tolerância com as diferenças, relações mais igualitárias, justiça e cidadania.

Mesmo tendo sido usado pelos capitalistas e burocratas como forma de apaziguar simbolicamente conflitos, levando o sujeito a acreditar que agora estava sendo convocado a participar da elaboração e dos planejamentos das políticas públicas sociais, a participação é uma forma de educar os sujeitos, visto que "ao participar, os indivíduos estariam submetidos a um processo de aprendizagem por meio do qual se capacitariam para intervir nas questões que lhes fossem solicitadas" (SILVA, 2003, p. 19).

Sendo assim, para que haja democracia, a participação entra como elemento materializador do projeto democrático através da partilha de poder, pois, "participar não significa assumir um poder, mas participar de um poder [...]” (MOTTA, 2003, p. 370). Os sujeitos que fazem parte do órgão representativo da sociedade, devem ter poder de deliberação e decisão que de forma inconsciente, não percebem a força que esse poder apresenta.

Para que haja participação o sujeito precisa ter conhecimento da realidade que surge com a experiência, saber como as coisas devem funcionar para poder opinar e habilidade política de como intervir. A forma como o sujeito participa das ações e decisão está relacionada com a forma de construção da cultura da participação ao longo da sua existência histórica.

Autores como Paro (2008), Barroso (1998), Bordignon e Gracindo (2006) Lück (2005) compartilham a ideia de que a participação como ação coletiva e autônoma é o instrumento de efetivação da democracia.

Revista de Administração Educacional, Recife, V. 1. № 2 - jul/dez. 2017 p. 37-48 
O conceito de participação, aqui entendido, parte de uma abordagem coletiva e consciente das ações dos sujeitos. Segundo Lück (2005, p. 17), participação é o espaço em que a sociedade é "envolvida no estabelecimento de objetivos, na solução de problemas, na tomada de decisões [...]”.

A cultura da participação deve ser construída, exercitada e repassada através de ações do cotidiano que contemplem o exercício da democracia. A garantia da democracia através da participação popular deve ser construída em todos os espaços sociais. Paro (2003, p. 100) afirma que “[...] como todo processo de democracia, a participação e o envolvimento das pessoas como sujeito na condução das ações é apenas uma possibilidade, não uma garantia."

Paro (2008) assevera que não existe um modelo pronto de participação, sendo assim, é necessário que cada sociedade construa seu modo de participar, com base na cultura que permeia as relações, em que participar é mais que executar é também a cima de tudo fazer parte da elaboração, do planejamento para que depois de executada cada ação possa ser avaliada por quem elaborou.

2.2 Presença/ausência da participação da sociedade no Plano Municipal de EducaçãoPME

De acordo com dados coletados através de questionários aos técnicos das Secretarias Municipais de Educação que fizeram parte do processo de elaboração do PME, um dos primeiros desafios foi sobre a participação dos demais membros das secretarias na fase de elaboração que demandou muito trabalho para a coleta de dados. A tarefa de participar da formação foi dada a alguns técnicos do setor de gestão e coordenação das secretarias, mas a responsabilidade era também de todos que faziam parte da secretaria e quando questionados sobre a participação dos demais membros das secretarias ainda $43 \%$ disseram que ainda não participavam da fase de elaboração.

Questionados sobre a sistemática de trabalho, a equipe informou quais espaços seriam construídos para garantir a participação da sociedade na fase de elaboração $44 \%$ afirmaram que a participação da sociedade se daria através de fóruns de debates, $28 \%$

Revista de Administração Educacional, Recife, V. 1. № 2 - jul/dez. 2017 p. 37-48 
através de comissão técnica e $26 \%$ seriam informados através de reuniões, apenas $2 \%$ deixaram em branco.

Como a primeira versão do plano, nos municípios alagoanos, contou com a presença de consultorias ${ }^{3}$, questionados sobre a elaboração da segunda versão do PME, 63\% afirmara que a segunda versão deu oportunidade, através dos instrumentos de participação como fóruns e comissões, a presença da sociedade nas discussões e elaboração do PME.

Durante as audiências que foram organizadas no município de Santana do Ipanema para a fase de discussão das metas e estratégias por cada modalidade de ensino, os participantes foram questionados sobre o motivo da presença na audiência e 64\% responderam que estavam participando da audiência porque foram indicados por suas respectivas instituições.

O fato de terem sidos indicados pelas instituições e não buscarem participar da audiência para conhecer como seria o PME e qual sua importância para a sociedade como um todo, revela a fragilidade da participação e levanta questões sobre o conceito de participação de quem estava presente.

A fragilidade da participação também se revela na falta de conhecimento da temática que estava sendo discutida na audiência e de toda a problemática envolvendo as políticas públicas quando questionados se a PME é uma política de governo ou de estado $81 \%$ disseram se tratar de uma política de governo e desses que responderam, $80 \%$ eram representantes de escolas.

E quando questionados sobre os principais problemas enfrentados na fase de elaboração do PME, 56\% afirmaram a ausência de participação da sociedade e $44 \%$ falta de apoio do governo.

Os dados apontam a dimensão da utilização da participação apenas para legitimar projetos e programas hierarquicamente programados para serem executados pela sociedade.

\footnotetext{
${ }^{3}$ Cf. SILVA, L. A. O plano municipal de educação como alinhamento dos planos de educação: o caso do sertão alagoano. In: SANTOS, I. M (org). Planejamento e Política Educacional: diferentes contextos e perspectivas. 2015.
}

Revista de Administração Educacional, Recife, V. 1. No 2 - jul/dez. 2017 p. 37-48 
Como o sujeito irá participar de decisões se desconhece o funcionamento da educação, das políticas públicas, de legislação, ele precisa estar instrumentalizado de forma a poder participar efetivamente. Entende-se por participação efetiva a atuação consciente do sujeito, ele sabe o motivo pelo qual está naquele momento, ele tem interesse em estar fazendo parte do momento, tem conhecimento do que está sendo discutido, consegue questionar e argumentar em defesa do seu ponto de vista.

Outro fator observado em relação a participação dos representantes dos diversos órgãos envolvidos legalmente via Portaria $n^{\circ}$. 114/2016, que designa os membros para integrar o Fórum Municipal de Educação, cuja representação vem da Secretaria Municipal de Educação, $6^{\mathrm{a}}$ Gerência Regional de Educação, Câmara Municipal de Vereadores, Conselho Municipal dos Direitos da Criança e Adolescente, Conselho Municipal de Educação, Conselho de Alimentação Escolar, Conselho do FUNDEB, Conselho Tutelar, Sindicato dos Trabalhadores da Educação de Alagoas, Representantes de Estudantes da Rede Pública/Privada de Santana do Ipanema, Gestores da Rede Pública, Gestores da Rede Privada, Professores da Rede Pública, Secretaria Municipal de Saúde, Secretaria Municipal de Assistência Social, Instituições de Ensino Superior Pública/Privada e Federal de Educação, Polo UAB de Santana do Ipanema, Secretaria Municipal de Finanças e Planejamento, Academia Santanense de Letras, Ciências e Artes, SWA Instituto, Associação dos Amigos e Pais de Pessoas Especiais, Associação dos Guardiões do Rio Ipanema, Secretaria Municipal de Obras, Saneamento, Transporte e Trânsito, Representantes das Igrejas Católica e Evangélica, que ao longo de dois anos de constituição apresentaram o seguinte perceptual de presença às reuniões.

Outra questão a ser refletida refere-se tanto ao índice de frequência dos representantes das instituições durante as assembleias e demais reuniões do fórum, como também, a mudança dos membros da comissão, que fizeram parte desde a fase de elaboração e monitoramento.

Quanto a participação/frequência dos membros da comissão às reuniões $27 \%$ nunca compareceram a uma reunião, motivo também pelo qual foram substituídos. Dos membros substituídos, que compunham a comissão, $80 \%$ foram substituídos pela mudança de governo municipal, visto que, 2016-2017 houve a transição governamental das cidades do pólo de Santana do Ipanema. Esse fato também aponta para a reflexão

Revista de Administração Educacional, Recife, V. 1. № 2 - jul/dez. 2017 p. 37-48 
sobre a influência partidária no processo de construção e execução das políticas públicas.

Contudo, e diante dos dados, percebe-se a necessidade de preparação da sociedade para que tenha condições e instrumentos que garantam a participação efetiva em todos os espaços e que dessa atuação consciente, seja construída uma cultura do compromisso e engajamento em relação às políticas públicas que são direcionadas para atendimento das demandas da sociedade.

\section{CONSIDERAÇÕES FINAIS}

Como a participação teve em seu histórico inicial a motivação de "controlar conflitos" (MOTTA, 1987), visto que as forças políticas, advindas de períodos ditatoriais, não encontram mais espaço para garantia do controle, entende-se que a participação efetiva é o caminho para a concretização da luta por melhorias, mas da forma como ela foi criada e nas configurações que se encontra na atualidade, não está apenas com o objetivo de controlar as massas enfurecidas, como serve mais ainda para legitimar ações de controle social.

Essa reflexão sinaliza para o fato das manifestações serem de forma intensa, em momentos de interesse de superiores hierárquicos do cenário político e econômico, e em outras ocasiões em que a população deveria participar com a mesma intensidade diante da gravidade da situação, ela se exime ou se manifesta de forma simplória sem significado na representação social, justificando a função social da participação popular que é legitimar, na maior parte das situações, o projeto hegemônico.

\section{REFERÊNCIAS}

AZEVEDO, Janete Maria Lins de. A educação como política pública. Campinas, SP: Autores Associados, 1997. 
BRASIL. Ministério da Educação e Cultura. Lei no 9.3694, de 20 de dezembro de 1996. Estabelece as diretrizes e bases da educação nacional. Diário Oficial da União, Brasília, 23 de dezembro de 1996.

Plano Nacional de Educação. Brasília: INEP, 1998.

Documento norteador para elaboração do Plano Municipal de EducaçãoPME. Elaboração: Clodoaldo José de Almeida Souza. Brasília: MEC, 2005.

MEC,2014.

O Plano Municipal de Educação. Caderno de Orientação. Brasília:

BORDIGNON, Genuíno; GRACINDO, Regina Vinhais. Gestão da educação: o município e a escola. In: FERREIRA, Naura Syria Carapeto; AGUIAR, Márcia Angela da S. (org.). Gestão da Educação: impasses, perspectivas e compromissos. 5 ed. São Paulo: Cortez, 2006.

Gestão da Educação no município: sistemas, conselhos e plano. São Paulo: Editora e Livraria Instituto Paulo Freire, 2009.

GHANEM, Elie. Educação escolar e democracia no Brasil. Belo Horizonte: Autêntica, 2004.

GOMES, Alfredo Macedo (org.). Políticas públicas e gestão da educação. Campinas, São Paulo: Mercado das letras, 2011.

GUTIERREZ, Gustavo Luiz. CATANI, Afrânio Mendes. Participação e gestão escolar: conceitos e potencialidades. In: FERREIRA, Naura Syria Carapeto (Org.). Gestão Democrática da Educação: atuais tendências, novos desafios. 3. ed. São Paulo: Cortez, 1998.

LÜCK, Heloísa. A escola participativa: o trabalho do gestor escolar. Petrópolis, RJ: Vozes, 2005.

MOTTA, Fernando C. Prestes. et al. Participação e participações: ensaios sobre autogestão. Babel Cultural: São Paulo, 1987.

Administração e participação: reflexões para a educação. Educação e Pesquisa. São Paulo, v. 29, n. 22, p. 369-373, jul/dez, 2003.

PARO, Vitor Henrique. Eleição de diretores: a escola pública experimenta a democracia. 2. Ed. São Paulo: Xamã, 2003.

Gestão democrática da escola pública. $3^{\text {a }}$ Ed. São Paulo: Ática, 2008.

Revista de Administração Educacional, Recife, V. 1. No 2 - jul/dez. 2017 p. 37-48 
ROMANELLI, Otaíza de Oliveira. História da educação no Brasil (1930-1973). Petrópolis: Vozes, 1991.

SANTOS, Ana Lúcia Félix dos. Gestão democrática da escola: bases epistemológicas, políticas e pedagógicas. In: GOMES, Alfredo Macedo (org.). Políticas públicas e gestão da educação. Campinas, São Paulo: Mercado das letras, 2011.

SANTOS, Isabela Macena. PRADO. Edna Maria do. Limites e possibilidades da formação de Gestores Escolares nos municípios alagoanos. Anais Colóquio

Internacional de Educação e Contemporâneidade, ISSN 1982365. Disponível em<http://educonse.com.br/viiicoloquio/> Acesso 27 out 2014.

SILVA, Ilse Gomes. Democracia e participação na reforma do estado. São Paulo, Cortez, 2003.

SILVA, Luciene Amaral. O plano municipal de educação como alinhamento dos planos de educação: o caso do sertão alagoano. In: SANTOS, Inalda Maria (org).

Planejamento e Política Educacional: diferentes contextos e perspectivas. 2015.

SAVIANI, Dermeval. A política educacional do Brasil. In: STHEFANOU, Maria e BASTOS, Maria Helena Câmara (orgs). Histórias e memórias da educação no Brasil. Petrópolis: Vozes, 2005. 